\title{
Попова В.H. \\ Роль бренд-айдентики во внутрикорпоративных отношениях на примере компании «Р.Д.Менеджмент сервисез»
}

Государственный университет управления

(Россия, Москва)

doi: $10.18411 / l j-02-2021-111$

idsp: ljournal-02-2021-111

\section{Аннотация}

В статье представлены результаты исследования влияния бренд-айдентики на корпоративные отношения. Объектом стала компания «Р.Д.Менеджмент сервисез», специализирующаяся на оказании услуг в области управления коммерческой недвижимостью. Автор делает выводы о том, какую роль играет фирменный стиль для внутрикорпоративных отношений.

Ключевые слова: бренд-айдентика, внутрикорпоративные отношения, компания, сотрудники

\section{Abstract}

The article presents the results of a study of the influence of brand identity on corporate relations. The object was the company "R.D. Management Services", specializing in the provision of services in the field of commercial real estate management. The author draws conclusions about the role of corporate identity for internal corporate relations.

Keywords: brand identity, internal corporate relations, company, employees

Наличие и развитие корпоративного фирменного стиля имеет определяющее значение для повышения конкурентоспособности, имиджа и узнаваемости компаний как в профессиональной среде, так и для потребителей товаров или услуг. При знакомстве с компанией клиент сталкивается, в первую очередь, с атрибутами бренда, с его отличительными чертами. Бренд-айдентика помогает наладить коммуникацию между компанией и клиентом, создает положительный образ в восприятии потребителя. Безусловно, бренд является более системным явлением, чем просто красивый запоминающийся логотип или форменная одежда сотрудников компании. Это ценностные ориентиры компании в сознании клиента. Однако без айдентики невозможно сформировать первое впечатление о компании.

Роль бренд-айдентики для внешней среды компании рассматривается широко. Важность логотипа как элемента визуальной идентичности бренда в рыночных условиях очевидна. В среднем каждый житель мегаполиса в течение дня сталкивается с 1200 логотипами. Логотип является первым коммуникатором компании, именно он олицетворяет историю, уникальность, ценности компании, которая стала брендом. [1] Понятие отличительных элементов бренда может рассматриваться в узком и широком смыслах. В узком смысле это такие составляющие как логотип, слоган, фирменный стиль. В широком смысле это рекламные сообщения, каналы распространения, медиастратегии. В настоящей статье айдентика бренда будет представлена в узкой понятийной направленности. К основным задачам, решаемым бренд-айдентикой, относят [2]:

- закрепление узнаваемого образа компании в глазах целевой аудитории;

- доступность для потребителя и легкая идентификация,

- выделение бренда среди конкурентов, привлечение к нему внимания.

Если бренд является узнаваемым и понятным, то велика вероятность формирования лояльного отношения со стороны потребителей и инвесторов. В качестве примера можно рассмотреть айдентику бренда Coca-Cola. Первые ассоциации с брендом, возникающие в сознании - Рождество, волшебство, Санта-Клаус, семья. Это 
система общечеловеческих ценностей, которая глубже и прочнее впечатлений, связанных с молодежными трендами, на которые опирается их конкурент - Pepsi, ассоциируясь, в первую очередь, с медийными личностями - Дэвидом Бекхэмом, Кристиной Агилерой, а также с молодежью, футболом, кинотеатрами. Сегодня СосаCola по версии Interbrand, является самым дорогим брендом на планете. Pepsi же занимает 26 место в списке. Таким образом, обеспечивается успешная коммерческая и публичная деятельность. [3] Другим примером значимости айдентики может стать бренд Nescafé. Для определения иерархии важности атрибутов бренда было проведено исследование среди офисных работников компании. Выборка составила 100 человек. В анкете были представлены 4 атрибута айдентики бренда: логотип, упаковка, фирменный стиль и POS-материалы, на которые чаще всего обращает внимание потребитель в точках продаж. По результатам проведённого анкетирования стало известно, что 37\% обращают внимание на упаковку, 32 \% на логотип, 20\% на POSматериалы в местах продаж и $11 \%$ на фирменный стиль. [4] Это лишний раз подтверждает факт, что визуальные элементы являются одним из определяющих факторов коммуникации с потребителем на рынке.

Сотрудники компании являются одной из целевых групп, с которой коммуницирует бренд: ежедневно они взаимодействуют, сознательно или бессознательно обращая внимания на фирменный стиль. При этом значимости брендайдентики для внутренней коммуникации уделяется недостаточно внимания. В настоящей статье будет рассмотрена значимость бренд-айдентики для внутрикорпоративных отношений на примере компании «Р.Д.Менеджмент сервисез», оказывающей полный комплекс услуг в области управления коммерческой недвижимости класса А.

Термин «бренд-айдентика» тесно связан с такими ключевыми понятиями, как визуальная составляющая бренда, инструмент для повышения узнаваемости, графические элементы, фирменный стиль. [5] Бренд-айдентика - это визуальная основа бренда, включающая в себя графические, акустические, осязательные и другие элементы, позволяющая выделить компанию среди других, а также помочь потребителю понять идею компании и пробудить в нем интерес к бренду. Фирменный стиль выражается во внешнем образе через единство формы (товарный знак, логотип, цветовая гамма и шрифт, деловая документация, рекламные материалы, оформление офиса), а также в единстве стиля поведения во внешней среде посредством проведения PR-акций, стимулирования сбыта, рекламных кампаний, переговоров с партнерами и личных продаж. [8]

Компания «Р.Д.Менеджмен сервисез» придерживается стратегии позиционирования. Потребителями являются арендаторы и владельцы бизнес-центров, которым важно иметь ясное представление о позиции компании. В социальных сетях и на официальном сайте постоянно присутствуют фразы, которые дают четко понять, как себя позиционирует компания. «Мы делаем объекты премиальными! Мы - это команда RD Management!», «Основные принципы работы RD Management - поддержание высоких стандартов обслуживания объектов и сохранение их инвестиционной стоимости». Компания «Р.Д.Менеджмент сервисез» имеет свою собственную разработанную айдентику. Логотип - визитная карточка компании, он присутствует на бланках деловых документов, в оформлении офиса, бейджах персонала, а также наносится на канцелярские принадлежности. Все сотрудники компании представляют, как выглядит их логотип, встречают его ежедневно и могут отличить от других логотипов. Помимо этого, в компании имеются корпоративные цвета, которые также сопровождают сотрудников в течение рабочего времени. Отдел маркетинга и связей с общественностью разрабатывает внутрикорпоративный журнал, доступный только для сотрудников. В нем обязательно присутствует логотип, он выполняется в фирменном стиле: шрифты, цвета, форматы - эти элементы позволяют компании выделяться. Для 
понимания значимости бренд-айдентики «Р.Д. Менеджмент сервисез» для внутрикорпоративных отношений был проведено глубинное интервью среди ключевых представителей основных целевых групп сотрудников компании. В анкетировании приняли участие:

- исполнительный директор - является компетентным в вопросах взаимоотношений внутри компании, участвует в организации мероприятий компании, имеет авторитетное мнение при выборе элементов айдентики;

- руководитель отдела маркетинга и связей с общественности, в его функционал входит управление созданием и поддержанием корпоративного стиля компании, участие в разработке элементов айдентики, организация внутрикорпоративных мероприятий;

- менеджер по подбору персонала - ответственен за взаимоотношения между сотрудниками и является компетентным в вопросах организационной психологии;

- дизайнер - занимается разработкой внешнего вида элементов брендайдентики компании, а также адаптацией их на различные носители.

Эксперты выразили единогласное мнение о важной роли бренд-айдентики для компании в целом, ее влиянии на взаимоотношения в коллективе, роль при организации мероприятий, а также влияние на отношение сотрудников к работе. Результаты глубинных интервью сформулированы ниже.

1. Бренд-айдентика направлена на построение успешных взаимоотношений с клиентом. Важны детали - от приветственных слов при входе в офис до атмосферы при совершении сделки. Эксперт отмечает: «Мы стараемся формировать стиль компании не только во внешнем виде сотрудников, но даже в канцелярских принадлежностях, настенных часах. Мы стараемся сделать так, чтобы клиент, глядя на наш стиль, сразу сформировал свое мнение и захотел работать с нами».

2. Имидж компании позволяет выделяться на рынке, делает ее конкурентоспособной. Разнообразие брендов и продуктов на современном рынке косметических средств заставляет потребителя тщательно выбирать товар, способный удовлетворить его потребности. Поэтому одной из основных задач производителя является не только создание близкого потребителю продукта, но и организация эффективных маркетинговых коммуникаций при взаимодействии с потребителем на рынке. [6] Выбирая из компаний, предоставляющих одинаковый спектр услуг, вероятность интереса потенциального клиента к той, где четко прослеживается единый стиль во всем, выше.

3. Бренд-айдентика способствует привлечению новых сотрудников в компанию. Наличие фирменного стиля сильнее мотивирует соискателя получить должность в компании.

4. Наличие элементов бренд-айдентики в компании делает общение сотрудников более деловым и нацеленным на результат. Сотрудники обращают внимание на корпоративные элементы и формируют общение с коллегами, ориентируясь и соответствуя стилю компании. Благодаря бренд-айдентике атмосфера в коллективе становится позитивной. Эксперты отмечают, что, приходя на работу и наблюдая повсюду логотип компании, фирменные цвета, у сотрудников улучшается настроение, возникает желание общаться с коллегами как с близкими людьми: «Приятно сидеть в офисе, где тебя окружает стиль. Сотрудники чувствуют важность своей работы, их взаимоотношения становятся более открытыми».

Отдельно стоит остановиться на роли бренд-айдентики в организации мероприятий компании. 
1. Все мероприятия, проводимые в компании, включают в себя элементы бренд-айдентики. Они могут присутствовать как в оформлении помещения, где проводится мероприятие, так и в рассылках, анонсирующих мероприятие, на раздаточных материалах, банкетном столе. Не являются исключением и корпоративы для сотрудников компании. Фирменный стиль создает атмосферу единства сотрудников, делает коллег сплоченными.

2. Мероприятия остаются в истории компании, а значит, клиенты и сотрудники будут обращать внимание на бренд-айдентику при просмотре новостей, фото и видео материалов. Даже незначительное внимание на элементы фирменного стиля позволят сформировать впечатление успеха, как мероприятия, так и компании в целом. «Проводя крупное мероприятие, необходимо помнить, что твои клиенты, сотрудники будут о нем говорить и вспоминать» - отмечают эксперты.

3. От качества проведенного мероприятия зависит дальнейшие отношения между сотрудниками. Если мероприятие проходит неудачно, сотрудники будут предъявлять претензии организаторам, то есть своим коллегам. В обратном случае организаторы получат благодарности и восторженные отзывы, а значит, взаимоотношения внутри компании улучшатся.

Не менее важным является мнение экспертов о влиянии бренд-айдентики на отношение сотрудников к работе. Здесь можно выделить следующие ключевые моменты.

1. Бренд-айдентика компании формирует настрой сотрудников на рабочий день. Эксперты отмечают, что нанесение логотипа компании на канцелярские принадлежности, бланки документов ежедневно оказывает позитивное психологическое влияние на сотрудников. В компании «Р.Д.Менеджмент сервисез» логотип в большом формате расположен сразу у входа в офис, что способствует моментальному переключению мыслей сотрудников с обыденности на рабочие вопросы.

2. Бренд-айдентика позволяет не только погружаться в работу, но и делать это с позитивом. У каждой компании свои корпоративные цвета. У «Р.Д. Менеджмент сервисез» это черный и синий. Эксперты утверждают, что именно эти цвета позволяют рабочему дню проходить позитивно и легко. Сотрудники чувствуют себя важным элементом компании, они уверены, что работают в серьезном месте и выполняют важную работу. Бренд-айдентика позволяет чувствовать себя причастным к успеху компании.

3. Бренд-айдентика компании влияет на качество работы. Сотрудники стараются соответствовать стилю, поэтому делают свою работу четко и усердно. Эксперты отмечают, что в компании, где все слаженно, в том числе есть и фирменный стиль, работа проходит успешно, соответствуя имиджу всей фирмы: «В хорошей и яркой компании хочется работать усердно, ради результата. Чтобы не подвести компанию, а наоборот повысить ее имидж».

4. Бренд-айдентика воспитывает в сотрудниках дисциплину. Чтобы соответствовать имиджу компании, сотрудники одеваются в соответствии с дресскодом, не опаздывают, не нарушают распорядок дня. Эксперты уверены: «Наша компания уверена, что наши сотрудники сами создают фирменный стиль своей работой».

Таким образом, бренд-айдентика в построении внутрикорпоративных отношений компании «Р.Д. Менеджмент сервисез» играет значимую роль. Для выживания в условиях высокой рыночной конкуренции компании вынуждены искать новые способы повышения капитализации брендов, создания механизмов лояльности и привлечения внимания покупателей. [7] Следует отметить, что теория ставит акцент на 
роли бренд-айдентики во внешних коммуникациях. Однако практика показывает, что роль во внутренних коммуникациях также важна.

$$
* * *
$$

1. Киуру К. Обновление логотипа как стратегия брендинга - Спб.: Брендинг как коммуникативная технология XIX века, 2018

2. Линдстром М. Чувство бренда. Воздействие на пять органов чувств для создания выдающихся брендов - М.: Эксмо, 2014

3. American Marketing Association - Режим доступа: http://www.ama.org

4. Чашленкова Е.В. Атрибуты айдентики бренда и их роль в формировании стратегии бренда. Научно-практический журнал «Аллея Науки» №7, 2017

5. Аакер Д. Создание сильных брендов. - М.: Изд. Гребенникова, 2012

6. Васильева О., Дергачева М. Особенности гендерного маркетинга на рынке косметических средств. Журнал «Наука и бизнес: пути развития» science and business: development ways № 8 (86) 2018 - с. $86-90$

7. Васильева О., Восканян И. Интерактивные маркетинговые технологии как тенденции развития рынка косметических услуг. Журнал «Наука и бизнес: пути развития» № 11 (101) 2019 - с. 124-129

8. Эйри Д. Логотип и фирменный стиль. Руководство дизайнера. - СПб.: Питер, 2013

\section{Свирин В.А. ${ }^{1}$, Герасимов Д.Д. ${ }^{2}$ \\ Интернет-маркетинг как инновационный вид маркетинговой деятельности \\ ${ }^{1}$ Владивостокский государственный университет экономики и сервиса \\ ${ }^{2}$ Дальневосточный федеральный университет}

(Россия, Владивосток)

doi: $10.18411 / l j-02-2021-112$

idsp: ljournal-02-2021-112

Аннотация

Интернет маркетинг - это вид классического маркетинга, который реализуется в онлайн-пространстве с возможностью получения обратной связи. В настоящей статье анализируется понятие интернет-маркетинга, приводится основная структура, составляющая интернет-маркетинга с существенными характеристиками таких элементов, как: реклама, SMM, SEO-продвижения, Еmail-маркетинга, Веб-аналитики, Контент-маркетинга.

Ключевые слова: интернет, маркетинг, интернет-маркетинг, продажи, сайты

\section{Abstract}

Internet marketing is a type of classic marketing that is implemented in the online space with the possibility of obtaining feedback. This article analyzes the concept of Internet marketing, provides the main structure that constitutes Internet marketing with essential characteristics of such elements as: advertising, SMM, SEO promotion, Email marketing, Web analytics, Content marketing.

Keywords: internet, marketing, internet marketing, sales, websites

В современном мире большое значение уделяется интернету и цифровым технологиям. Люди всё больше времени проводят в социальных сетях и за монитором компьютера. Сейчас потребители, всё реже посещают магазины и выходят на интернет площадки, выбирая всё вплоть от еды и заканчивая одеждой. Такие площадки по покупке различных товаров, как Ozon и Wildberries, в России имеют в сутки миллионы запросов от пользователей. Для людей это не просто удобно и сокращает время на поездку в магазин, а также выгодно, ведь чаще всего товар, продаваемый в интернете стоит гораздо дешевле нежели на полках супермаркетов. Это связано с тем, что при такой продаже издержки (от затрат на заработную плату сотрудникам магазина и до арендной платы за землю) меньше и, следовательно, уменьшается стоимость покупок. 